\title{
Did the extended coverage policy contribute to alleviating socioeconomic inequality in untreated dental caries of both children and adolescents in South Korea?
}

\section{Bo-Mi Shin}

Gangneung-Wonju National University College of Dentistry

\section{Se-Hwang Jung}

Gangneung-Wonju National University College of Dentistry

\section{Myong-Hee Kim}

People's Health Institute

Jae-ln Ryu ( $\square$ jaeinryu@khu.ac.kr)

Kyung Hee University College of Dentistry https://orcid.org/0000-0002-1923-8030

\section{Research article}

Keywords: Children and adolescent health; socioeconomic factors; inequality; service provision.

Posted Date: April 15th, 2020

DOI: https://doi.org/10.21203/rs.2.20733/v3

License: (c) (i) This work is licensed under a Creative Commons Attribution 4.0 International License. Read Full License

Version of Record: A version of this preprint was published at BMC Oral Health on April 22nd, 2020. See the published version at https://doi.org/10.1186/s12903-020-01112-8. 


\section{Abstract}

Background Dental sealants have been covered by the National Health Insurance Service (NHIS) since December 2009 in South Korea. This study aims to determine whether the socioeconomic inequality in untreated dental caries decreased after implementing the extended coverage policy for dental sealant.

Methods The data were derived from the fourth (2007-2009) and sixth (2013-2015) waves of the Korean National Health and Nutrition Examination Survey (KNHANES) conducted by the Korea Centers for Disease Control and Prevention (KCDC). Dental caries and sealant experience by income quartiles were tested using the Rao-Scott chi-squared test. In order to examine socioeconomic inequalities and their trends over time, the prevalence ratios (PRs), slope index of inequality (SII), and relative index of inequality (RII) were estimated for each wave and age group. All analyses were conducted using SAS version 9.3.

Results The adjusted PRs of untreated dental caries and sealants in the poorest in the aged 6-11 group were significantly higher and lower, respectively, compared to the most affluent quartile group for the fourth wave; however, all significant differences disappeared for the sixth wave, after the sealant coverage. The gap between the lowest and the highest was similar for the aged 12-18 group but it widened in the untreated dental caries even after the sealant coverage. The statistical significance of the PRs was maintained at the sixth wave for both caries and sealants. Children showed decreases in both SII and RII over time so its significance disappeared. The SIl among adolescents decreased over time but the RII of untreated dental caries increased.

Conclusions This study found that the NHIS coverage expansion of dental care had a positive effect on overall status in dental health among children and adolescents. However, younger children benefited more in terms of inequalities. Our findings indicate that strategies to enhance access to preventive dental services should consider the differential effects for the vulnerable population in terms of socioeconomic status and age from the beginning stage of the policy.

\section{Background}

Dental caries is the tenth most prevalent disease in the world, representing a significant burden of disease, especially in children [1,2]. More than a quarter of the global population, almost 2.4 billion, suffer from untreated dental caries. Moreover, it is very expensive, as shown to be the fourth most expensive disease for effective treatment [3]. The bigger issue is that oral health conditions often indicate socioeconomic inequalities. A previous systematic review revealed that an individual's socioeconomic position (SEP), such as parental or own education, occupation, and family income, was significantly associated with dental caries [4]. Those with higher SEP had a lower risk of having or having experienced dental caries.

Preventive care is the most effective way to minimize both the health and financial burdens of untreated caries. Dental sealants and fluoride applications are common and effective methods for preventing 
dental caries [5]. In the United States, school-based programs provide sealants to children, especially for subsidized meal program recipients [6]. Students who did not receive sealant treatment showed a two to three time higher mean numbers of decayed or filled first molars than students who did [7]. They suggested that universal caries prevention could reduce the incidence of dental caries by up to $80 \%$, leading to savings on dental expenses [8]. A Chinese cohort study also showed that the hazard ratio for dental caries was 0.6 times lower in the treatment group received sealants compared to the control group [9].

However, a Dutch study showed undesirable outcomes regarding socioeconomic inequalities in dental health in spite of the expansion of dental care coverage. The Netherlands' government offers free dental services for individuals under nineteen years old and most of the participants visited dental professionals almost every year. Even after the expansion children in low SEP still had 1.5 times higher risk of having caries than children in higher SEP. This gap persisted beyond childhood and continued until they were young adults [10]. Similar results were found in Sweden, where the government provides free dental services for children and adolescents. The children in lower SEP had two to five times higher odds ratios of having dental caries than the higher SEP group, controlling for covariates such as ethnicity, wealth, parental education, and employment [11]. A meta-analysis also reported that developed countries with relatively equal income distribution showed more unequal caries experience, compared to developing countries with unequal income distribution [4]. These inconsistent findings suggest that there must be diverse factors related to the prevalence or experience of dental caries and that similar factors might have different effects, depending upon countries' health care systems and their economic development status [12-14].

In South Korea (hereafter, Korea), dental sealants have been covered by the National Health Insurance Service (NHIS) since December 2009 [15]. In the beginning, the policy offered limited coverage, only the first molars of children aged 6 to 14. In May 2013, the coverage was expanded up to the second molars of children up to 18 years old. Accordingly, the proportion of children aged 6-14 years who received dental sealant increased encouragingly, from $28.7 \%$ to $34.9 \%$ [16]. A Korean study reported that after the policy implementation, dental sealant increased and untreated caries decreased, especially among lower SEP groups [17]. Many existing studies have suggested that equal access to dental treatment is essential to improve the dental status of all [18]. However, there is a gap in the literature concerning whether these governmental policies contribute to alleviating inequality in children's oral health [19].

This study aims to determine whether the socioeconomic inequality in untreated dental caries decreased after implementing the extended coverage policy for dental sealant in South Korea.

\section{Methods}

\section{Study design and participants}

The data were derived from the fourth (2007-2009) and sixth (2013-2015) waves of the Korean National Health and Nutrition Examination Survey (KNHANES) conducted by the Korea Centers for 
Disease Control and Prevention (KCDC). The KNHANES is a repeated cross-sectional survey on a representative national sample that is based on multi-stage clustered probability samples from Korean households representing the civilian non-institutionalized population aged one year and older [20]. Each year, 192 sampling units and 20 households per primary sampling unit are selected according to location, age, and gender, yielding approximately 10,000 subjects in the age group.

The research team sent the written notice for examinations and surveys to selected household members with a brief introduction. Only the members who agreed to participate with written ethical approval and consent forms, acquired from themselves or their guardians if they were under fourteen-year-olds, were included in this study,

The survey consists of a health examination, a health interview, and a nutrition survey. It also includes an oral health examination by a dentist and a questionnaire interview regarding oral health behaviors. The KNHANES is certified and used as the national statistics by the Korea Department of Statistics. The raw data of the KNHANES are publicly available on their official website [21]. For the samples used in this study, the response rates were $78.4 \%$ in the fourth [22-24] and $78.3 \%$ in the sixth-wave [25-27], respectively. A total of 50,405 individuals participated, with informed consent. This study analyzed data from 7,410 participants aged 6-18 years old (4,353 in the fourth and 2,915 in the sixth-wave) after excluding 1,040 individuals due to missing information about oral health status, household income, and dental health behaviors. The study participants were divided into two groups: children aged 6-11 years old and adolescents aged 12-18 years old. In South Korea, the children enter the elementary school at 6, the middle school at 12, and high school at 15 . The children and adolescents were separated because the coverage of the dental sealant in South Korea started from the children aged 6 to 14 then extended up to 18-year-old adolescents later. They were expected to show different patterns in untreated dental caries by the policy change. The Institutional Review Board of Gangneung-Wonju National University reviewed and approved this study (GWNUIRB-2016-07).

\section{Data Variables}

We set the outcome variables as dental caries and sealant experience, evaluated by dentists based on WHO criteria, who had completed the calibration training program and carried out clinical oral examinations in the mobile health examination centers [28]. For the dentist calibration training, the dental status measures were validated by comparing it with a reference dentist. As inter-examiner reliabilities, the mean Kappa values for tooth status were 0.711 to 0.919 by 47 dentists in the fourth [29-31] and 0.892 to 0.939 by 90 dentists in the sixth-wave [32-34]. Socioeconomic variables included household monthly income, equivalized for household size (equivalent household income $=$ total household income $\div$ [household size ${ }^{0.5}$ ) and categorized into four quartiles. Dental health behaviors were considered as potential mediators to the relationship between income and dental health, while age and gender were considered as confounders. The frequency of tooth brushing (FTB) was categorized into two groups: brushing less than twice a day vs. two or more times a day. Regular dental check-ups (RDC) was 
classified as yes or no, asking whether they had visited the dentist for a regular check-up without any symptoms during the year prior to the interview.

\section{Data analysis}

We used a complex sample analysis method to consider complex sample designs, including primary sampling units, stratification, and sample weights. The oral health conditions by income quartiles were tested using the Rao-Scott chi-squared test (Proc Surveyfreq). In order to examine socioeconomic inequalities and their trends over time, the prevalence ratios (PRs), slope index of inequality (SII), and relative index of inequality (RII) were estimated for each wave and age group. All the analyses were done twice as Model 1 adjusted with age and gender and Model 2 adjusted with age, gender, and dental health behavior such as FTB (frequency of tooth brushing) and RDC (regular dental check-up). The PRs and 95\% confidence intervals (Cls) were estimated to assess the association between household income quartiles and untreated dental caries or sealant experiences in Korean children. SII represents the absolute difference in values between the lowest and the highest ends of SEP [35], while RII represents the ratio of the prevalence between the highest and lowest ends [35-37]. SII and RII were calculated using the relative income position indicator on the cumulative distribution of age-group specific equivalized income. This relative position indicator is a value between 0 and 1 , allocated by calculating the mid-point of the relative position in the cumulative population distribution in income group, and was used as an independent variable in the log-binomial regression analyses. The LINK IDENTITY option of Proc GENMOD in SAS was used to calculate SII, while the LINK LOG option was used for calculating RII and PR [38, 39]. All analyses were conducted using SAS version 9.3 (SAS Institute Inc., Cary, NC, USA). All the models converged within the availability of the calculations of PR, SII, and RII.

\section{Results}

The general characteristics of the study participants are shown in Table 1. The gender and income distribution of both age groups were similar at the fourth and sixth wave, respectively.

Table 1 Study Sample Characteristics: $N$ (\%) 


\begin{tabular}{lcccccc}
\hline & \multicolumn{2}{c}{ Children aged 6-11 } & \multicolumn{3}{c}{ Adolescents aged 12-18 } \\
\hline Variables & $2007-09$ & $2013-15$ & $P$-value & $2007-09$ & $2013-15$ & $P$-value \\
\hline Total & $2,240(100)$ & $1,449(100)$ & $2,113(100)$ & $1,466(100)$ & \\
\hline Gender & & & & & & \\
\hline Male & $1,167(52.1)$ & $758(51.9)$ & 0.937 & $1,113(53.7)$ & $812(52.1)$ & 0.572 \\
\hline Female & $1,073(47.9)$ & $691(48.1)$ & $1,000(46.3)$ & $718(47.9)$ & \\
\hline Income level & & & & & & \\
\hline I (lowest) & $553(24.9)$ & $347(23.7)$ & 0.671 & $524(24.8)$ & $348(25.0)$ & 0.872 \\
\hline$\square$ & $544(23.9)$ & $359(26.7)$ & $518(24.8)$ & $363(25.1)$ & \\
\hline$\square$ & $568(25.3)$ & $368(25.2)$ & $522(24.8)$ & $391(25.7)$ & \\
\hline$\square$ (highest) & $575(25.9)$ & $375(24.4)$ & $549(25.6)$ & $364(24.2)$ & \\
\hline FTB & & & & & \\
\hline$<2$ & $308(13.8)$ & $117(7.9)<0.001$ & $261(12.3)$ & $108(7.7)$ & $<0.001$ \\
\hline$\geq 2$ & $1,932(86.2)$ & $1,332(92.1)$ & $1,852(87.7)$ & $1,358(92.3)$ & \\
\hline RDC & & & & & & \\
\hline No & $755(32.2)$ & $427(28.4)$ & 0.116 & $1,124(53.4)$ & $820(57.3)$ & 0.025 \\
\hline Yes & $1,485(67.8)$ & $1,022(71.6)$ & $989(46.6)$ & $646(42.7)$ & \\
\hline
\end{tabular}

$P$-values were obtained from complex samples crosstabs: Rao-Scott chi-squared test.

Values are presented by weighted prevalence \% (95\% CI).

FTB (frequency of tooth brushing) and RDC (regular dental check-ups)

Table 2 shows the prevalence of untreated dental caries and sealant by gender and household income. The prevalence of untreated dental caries decreased in both age groups and all the income groups over time, except for the highest income quartile of the children. In contrast, the sealant prevalence increased over time across all ages and income groups. For the fourth wave, there was a significant socioeconomic inequality in untreated dental caries and sealant prevalence in both age groups; however, for the sixth wave, there was no significant difference among the aged 6-11 group.

Table 2. Prevalence rates $(95 \% \mathrm{CI})$ of untreated dental caries and sealant by income level 
30.0)

\begin{tabular}{|c|c|c|c|c|c|c|}
\hline$\geq 2$ & $\begin{array}{c}31.6(28.8- \\
34.4)\end{array}$ & $41.2(37.8-44.6)$ & 9.7 & $27.7(25.0-30.3)$ & $37.1(33.8-40.4)$ & 9.4 \\
\hline$P$-value & 0.024 & 0.240 & & 0.020 & 0.789 & \\
\hline \multicolumn{7}{|l|}{ RDC } \\
\hline No & $\begin{array}{c}24.8(20.7- \\
28.9)\end{array}$ & $36.1(30.3-41.9)$ & 11.3 & $21.9(18.8-25.0)$ & $33.4(29.5-37.3)$ & 11.6 \\
\hline Yes & $\begin{array}{c}33.4(30.3- \\
36.5)\end{array}$ & $42.6(38.9-46.3)$ & 9.2 & $32.4(28.7-36.1)$ & $41.7(37.2-46.2)$ & 9.4 \\
\hline$P$-value & 0.001 & 0.062 & & $<0.001$ & 0.003 & \\
\hline
\end{tabular}

$P$-values were obtained from complex samples crosstabs: Rao-Scott chi-squared test.

Values are presented by weighted prevalence \% (95\% CI).

FTB (frequency of tooth brushing) and RDC (regular dental check-ups)

Table 3 shows the adjusted PRs of untreated dental caries and sealants by income quartiles for the fourth and sixth waves. The adjusted PRs of untreated dental caries and sealants in the lowest income quartile in the aged 6-11 group were significantly higher or lower, respectively, compared to the highest quartile group for the fourth wave; however, all significant differences disappeared for the sixth wave, after the sealant coverage. The gap between the lowest and the highest was similar for the aged 12-18 group but it widened in the untreated dental caries even after the sealant coverage. The statistical significance of the PRs was maintained at the sixth wave for both caries and sealants.

Table 4 shows the absolute and relative inequalities in untreated dental caries and sealant prevalence in both age groups by income quartiles. The changing pattern of SII and RII for sealant and untreated dental caries prevalence were different in two age groups between the fourth and the sixth wave. Children showed alleviates in both SII and RII over time and its significance disappeared. The SII among adolescents decreased over time, for example, from 16.4 (95\% Cl: 9.6-23.2) to 13.9 (95\% Cl: 6.5-21.2) as well. However, the RII of untreated dental caries increased from $1.7(95 \% \mathrm{Cl}: 1.4-2.2)$ to 2.1 (95\% Cl: $1.5-$ 2.9) exceptionally.

Table 3. Changes in prevalence ratios (PRs) (95\% CI) of untreated dental caries and sealant by income level 


\begin{tabular}{|c|c|c|c|c|c|c|c|c|}
\hline & \multicolumn{4}{|c|}{ Children aged 6-11 } & \multicolumn{4}{|c|}{ Adolescents aged 12-18 } \\
\hline & \multicolumn{2}{|c|}{$2007-09$} & \multicolumn{2}{|c|}{ 2013-15 } & \multicolumn{2}{|c|}{ 2007-09 } & \multicolumn{2}{|c|}{ 2013-15 } \\
\hline & Model $1^{\mathrm{a}}$ & Model $2^{\mathrm{b}}$ & Model $1^{\mathrm{a}}$ & Model $2^{\text {b }}$ & Model $1^{\mathrm{a}}$ & Model $2^{b}$ & Model $1^{\mathrm{a}}$ & Model $2^{\mathrm{b}}$ \\
\hline \multicolumn{9}{|c|}{ Untreated dental caries } \\
\hline \multicolumn{9}{|c|}{ Income level } \\
\hline \multirow[t]{2}{*}{ I (lowest) } & 2.29 & 2.11 & $1.12(0.64$ & $1.10(0.62$ & $1.47(1.24$, & $1.44(1.22$ & $1.77(1.37$ & $1.67(1.28$, \\
\hline & $3.50)^{* * *}$ & $3.23)^{* * *}$ & $1.96)^{\mathrm{NS}}$ & $1.93)^{\mathrm{NS}}$ & $1.74)^{* * *}$ & $1.71)^{* * *}$ & $2.32)^{* * *}$ & $2.18)^{* * *}$ \\
\hline \multirow[t]{2}{*}{ प } & 2.18 & $2.14(1.40$ & $0.91(0.51$ & $0.91(0.51$ & $1.12(0.93$, & $1.11(0.92$ & $1.19(0.88$ & $1.15(0.85$, \\
\hline & $3.34)^{* * *}$ & $3.28)^{* * *}$ & $1.63)^{\mathrm{NS}}$ & $1.63)^{\mathrm{NS}}$ & $1.35)^{\mathrm{NS}}$ & $1.33)^{\mathrm{NS}}$ & $1.59)^{\mathrm{NS}}$ & $1.54)^{\mathrm{NS}}$ \\
\hline \multirow[t]{2}{*}{ III } & $1.44(0.91$ & $1.44(0.91$ & $0.66(0.35$ & $0.67(0.36$ & $0.96(0.79$, & $0.96(0.79$ & $1.17(0.87$ & $1.16(0.87$, \\
\hline & $2.27)^{\mathrm{NS}}$ & $2.27)^{\mathrm{NS}}$ & $1.25)^{\mathrm{NS}}$ & $1.27)^{\mathrm{NS}}$ & $1.17)^{\mathrm{NS}}$ & $1.17)^{\mathrm{NS}}$ & $1.56)^{\mathrm{NS}}$ & $1.55)^{\mathrm{NS}}$ \\
\hline \multicolumn{2}{|c|}{ (highest) 1.00} & 1.00 & 1.00 & 1.00 & 1.00 & 1.00 & 1.00 & 1.00 \\
\hline \multicolumn{9}{|c|}{ Sealants } \\
\hline \multicolumn{9}{|l|}{ Income level } \\
\hline I (lowest) & $\begin{array}{l}0.70(0.59 \\
0.85)^{* * *}\end{array}$ & $\begin{array}{l}0.73(0.61 \\
0.88)^{* * *}\end{array}$ & $\begin{array}{l}0.90(0.76 \\
1.06)^{\mathrm{NS}}\end{array}$ & $\begin{array}{l}0.92(0.78 \\
1.09)^{\mathrm{NS}}\end{array}$ & $\begin{array}{l}0.54(0.45, \\
0.66)^{* * *}\end{array}$ & $\begin{array}{l}0.57(0.47 \\
0.70)^{* * *}\end{array}$ & $\begin{array}{l}0.70(0.58 \\
0.85)^{* * *}\end{array}$ & $\begin{array}{l}0.70(0.58, \\
0.86)^{* * *}\end{array}$ \\
\hline \multirow[t]{2}{*}{ II } & $0.88(0.74$ & $0.89(0.75$ & $0.89(0.75$ & 0.90 & $0.68(0.57$, & $0.71(0.59$ & $0.86(0.73$ & $0.87(0.73$, \\
\hline & $1.03)^{\mathrm{NS}}$ & $1.04)^{\mathrm{NS}}$ & $1.04)^{\mathrm{NS}}$ & $1.06)^{\mathrm{NS}}$ & $0.82)^{* * *}$ & $0.84)^{* * *}$ & $1.03)^{\mathrm{NS}}$ & $1.03)^{\mathrm{NS}}$ \\
\hline \multirow[t]{2}{*}{ III } & 0.89 & $0.90(0.76$ & $1.01(0.86$ & $1.01(0.87$ & $0.85(0.72$, & 0.85 & 0.86 & $0.86(0.73$, \\
\hline & $(1.05)^{\mathrm{NS}}$ & $1.05)^{\mathrm{NS}}$ & $1.18)^{\mathrm{NS}}$ & $1.18)^{\mathrm{NS}}$ & $1.00)^{*}$ & $1.00)^{\mathrm{NS}}$ & $1.02)^{\mathrm{NS}}$ & $1.01)^{\mathrm{NS}}$ \\
\hline $\begin{array}{c}\text { IV } \\
\text { (highest) }\end{array}$ & 1.00 & 1.00 & 1.00 & 1.00 & 1.00 & 1.00 & 1.00 & 1.00 \\
\hline
\end{tabular}

a Adjusted for age, gender.

$\mathrm{b}$ Adjusted for age, gender, FTB (frequency of tooth brushing), and RDC (regular dental check-up)

* $P<0.05$, ** $P<0.01$, *** $P<0.001$

Table 4. Absolute and Relative socio-economic inequalities (95\% CI) of untreated dental caries and sealant by income level 


\begin{tabular}{|c|c|c|c|c|c|c|}
\hline 2007-09 & & 2013 & & & 7-09 & 2013-15 \\
\hline Model 1 ${ }^{\mathrm{a}}$ & Model $2^{b}$ & Model $1^{\mathrm{a}}$ & Model $2^{b}$ & $\begin{array}{c}\text { Model } \\
1^{\mathrm{a}}\end{array}$ & Model $2^{b}$ & Model $1^{\mathrm{a}}$ \\
\hline
\end{tabular}

\begin{tabular}{|c|c|c|c|c|c|c|c|c|}
\hline \multicolumn{9}{|c|}{$\begin{array}{l}\text { Untreated } \\
\text { caries }\end{array}$} \\
\hline SII & $\begin{array}{l}7.3)^{(3.3,} \\
11.3)^{* * *}\end{array}$ & $\begin{array}{l}7.0 \quad(2.8 \\
11.2)^{* *}\end{array}$ & $\begin{array}{l}0.8(-3.3 \\
4.8)^{\mathrm{NS}}\end{array}$ & $\begin{array}{l}0.4(-3.6, \\
4.4)^{\mathrm{NS}}\end{array}$ & $\begin{array}{l}16.4 \\
23.2)^{* * *}\end{array}$ & $\begin{array}{l}15.9 \\
22.7)^{* * *}\end{array}$ & $\begin{array}{l}13.9 \\
21.2)^{* * *}\end{array}$ & $\begin{array}{l}11.7 \text { (4.3 }^{(4.2)^{* *}}\end{array}$ \\
\hline RII & $\begin{array}{l}3.1 \text { (1.9, } \\
5.0)^{* * *}\end{array}$ & $\begin{array}{l}2.7(1.7 \\
4.5)^{* * *}\end{array}$ & $\begin{array}{l}1.2(0.6, \\
2.6)^{\mathrm{NS}}\end{array}$ & $\begin{array}{l}1.2(0.5, \\
2.5)^{\mathrm{NS}}\end{array}$ & $\begin{array}{c}1.7 \\
2.2)^{* * *}\end{array}$ & $\begin{array}{c}1.7 \\
2.1)^{* * *}\end{array}$ & $\begin{array}{l}2.1 \\
2.9)^{* * *}\end{array}$ & $\begin{array}{l}1.9 \\
2.6)^{* * *}\end{array}$ \\
\hline \multicolumn{9}{|c|}{ Sealants } \\
\hline SII & $\begin{array}{l}-11.7 \\
(-18.1 \\
-5.4)^{* * *}\end{array}$ & $\begin{array}{l}-9.3 \\
(-16.4 \\
-2.2)^{* *}\end{array}$ & $\begin{array}{l}-7.1 \\
(-15.2 \\
0.9)^{\mathrm{NS}}\end{array}$ & $\begin{array}{l}-5.0 \\
(-13.2 \\
3.1)^{\mathrm{NS}}\end{array}$ & $\begin{array}{l}-20.9(-27.6 \\
-14.3)^{* * *}\end{array}$ & $\begin{array}{l}-18.1 \\
(-24.8 \\
-11.4)^{* * *}\end{array}$ & $\begin{array}{l}-14.9 \\
(-23.7 \\
-6.2)^{* * *}\end{array}$ & $\begin{array}{l}-14.3 \\
(-23.1 \\
-5.4)^{* *}\end{array}$ \\
\hline RII & $0.7)^{(0.5}$ & $\begin{array}{l}0.7(0.6 \\
0.9)^{* * *}\end{array}$ & $\begin{array}{l}0.8(0.7 \\
1.0)^{\mathrm{NS}}\end{array}$ & $\begin{array}{l}0.9(0.7 \\
1.1)^{\mathrm{NS}}\end{array}$ & $\begin{array}{c}0.5 \\
0.6)^{* * *}\end{array}$ & $\begin{array}{c}0.5 \\
0.6)^{* * *}\end{array}$ & $\begin{array}{l}0.7(0.5, \\
0.9)^{* *}\end{array}$ & $\begin{array}{l}0.7(0.5 \text {, } \\
0.9)^{* *}\end{array}$ \\
\hline
\end{tabular}

a Adjusted for age, gender.

$\mathrm{b}$ Adjusted for age, gender, FTB (frequency of tooth brushing), and RDC (regular dental check-up)

$* P<0.05, * * P<0.01, * * * P<0.001$

\section{Discussion}

This study found that socioeconomic inequality in untreated dental caries and sealant treatment was alleviated for children by an expansion of NHIS coverage in Korea.

The data from KNHANES were analyzed, which is a yearly repeated cross-sectional survey and the data for every three years represent a different wave. The survey continues for three years, which offers the advantage of reflecting fast-changing disease patterns. There could be slight differences every year, meaning that it is imperative that data are handled carefully [20]. This was the reason to analyze this data to compare before and after the policy implementations such as natural experiments. It can be assumed that the changes of Korean people could be found by this sample. Another advantage of this survey is carefully designed to be representative of national non-institutionalized civilians in South Korea. Well-trained dentists took part in this survey which makes the result stronger and reliable. The survey is repeated every year with different samples, not like a cohort. It could be a strength of this survey because the cohort might be impossible to reflect the change of the caries trends with representative samplings. The different characteristics of the fourth and sixth wave samples were applied to the data set with caries and sealant status changes.

After the coverage expansion of dental sealants, the prevalence of untreated dental caries decreased and that of having sealant treatment increased in both children and adolescents. This study also showed an overall increase in dental service usage after the coverage expansion [17]. A similar review on smoking 
inequality in youth after tobacco control policies concluded that [40] education and information communication led to widening inequalities, while the tobacco price policy reduced socioeconomic inequalities. This is supported by the argument that some public health interventions may increase inequalities [41]. "Upstream" interventions such as reducing price barriers are more likely to have positive effects on alleviating inequalities compared to "downstream" interventions to focus on individual-level factors such as information provided through education. Based on the review of the effects of public health policies on health inequalities, Thomson et al. [42] concluded that two types of oral health interventions had positive effects on inequalities: water fluoridation [43] and a national tooth brushing education campaign [44]. Another study pointed out that dental insurance is an important driver for dental service use, as tackling financial barriers mostly reduces unmet dental needs $[17,45]$. US studies to examine the effects of the Children's Health Insurance Program also reported an increase in sealant treatment, fluoride tablets, and dental visits and a decrease in untreated caries since 1997, especially in children from lower-income households who benefited from free or subsidized school lunch programs [46].

The present study showed differential impacts of coverage expansion on dental health inequality between children and adolescents; the alleviation of inequalities was more salient among children while not among adolescents, especially in untreated dental care. The adolescent group showed decreased prevalence both in the untreated dental caries and sealant. However, the proportional changes in caries were not enough to narrow the gap between the highest and the lowest income groups in adolescents. A difference could be explained as follows. First, inequality may worsen as children grow older, as shown in previous studies [47-50]. A study based on the United Kingdom Millennium Cohort showed relatively narrow in health inequality when the children were younger (aged 3-5) [47]. They were born when the New Labor Government introduced a sustainable strategy to address health inequalities. It could be inferred that the use of preventive dental services may alleviate the disease. Even the same intervention could not have the same effect on older children to alleviate inequality. The second possibility is the 'inverse care law' of public health care [51-54]. In the early stage, public health care is used by people with more resources such as information, time, availability, or money, which leads to deepening inequalities. The NHIS dental care coverage in South Korea was implemented in December 2009, and it covered only children aged 6-14 years old for the first molar in permanent dentition with a $30 \%$ copayment. In 2012, the coverage was expanded to the second molar and adolescents up to 18 years old in 2013. The adolescents aged 12-18 in the sixth wave were 6-12 years old in the fourth wave (2007-2009). A part of them was not eligible for the service because they were over 14, not qualified for the service until 2013. Later the service was available to all, but some of them already had or had experienced caries, in which dental sealants were no longer applicable. Third, as McLaren pointed out, sometimes the population strategy of prevention will not be effective in narrowing socioeconomic inequalities in health [55]. Preventive services such as sealant treatment could inhibit dental caries, but it is not guaranteed to reduce socioeconomic inequalities in oral health [56]. Based on Taiwan's National Health Insurance Research Database, Hsu et al. showed that including the preventive provision of fluoride has an effect, but only for specific groups of children who are vulnerable to dental problems [57]. Even though the 
percentage of children receiving fluoride was increasing, visits for dental caries decreased among those with highly severe caries of primary dentition. One UK study also showed that socioeconomic inequality remained despite no difference in dental health utilization [58]. In the United States, income-related inequality in untreated dental caries among children has been steady over three decades since the 1970s $[48,49]$. More salient inequality in dental health observed in developed countries rather than developing ones [4] may be associated with accessibility to dental treatment services as well as sugar consumption [50].

There are several limitations of this study related to the coverage of dental sealants. The NHIS policy changes too often in relation to dental sealant treatment. From the 2010 s, the government just agreed on an extension of the coverage provided for dental care to include preventive treatment for the first time. This has not been implemented before, as the government was wary of the possible financial burden. However, their expectations proved to be inaccurate, as fewer than $10 \%$ of children received the dental sealant service under the policy coverage every year. Because it was a new approach, the policy went through a transitional phase concerning the extended coverage of dental service in the beginning. This means that the change in policy could have affected the children and adolescents in this study unevenly. Later, in 2017 , the government reduced the out-of-pocket payment from $30 \%$ to $10 \%$ of the total fee. This limitation can be overcome if monitoring of next wave study participants continues.

\section{Conclusion}

This study found that the NHIS coverage expansion of dental care had a positive effect on overall status in dental health among children and adolescents. However, younger children benefited more in terms of inequalities. Our findings indicate that strategies to enhance access to preventive dental services should consider the differential effects for the vulnerable population in terms of socioeconomic status and age from the beginning stage of the policy. The extended coverage policy should continue, focusing on the underprivileged and young children population.

\section{List Of Abbreviations}

SEP: Socioeconomic Position; Korea: South Korea; NHIS: National Health Insurance Service (NHIS); KNHANES: Korean National Health and Nutrition Examination Survey; KCDC: Korea Centers for Disease Control and Prevention; WHO: World Health Organization; FTB: Frequency of Tooth Brushing; RDC: Regular dental check-ups; PRs: Prevalence Ratios; SII: Slope Index of Inequality; RII: Relative Index of Inequality; Cls: Confidence Intervals

\section{Declarations}

Ethics approval and consent to participate 
- This study used data from the fourth (2007-2009) and sixth (2013-2015) Korean National Health and Nutrition Examination Survey (KNHANES) conducted by the Korea Centers for Disease Control and Prevention (KCDC) that written informed consent was obtained from participants and a parent or guardian for participants under 14 years old. The KCDC acquired ethical approvals from its own Institutional Review Board (IRB) for the KNHANES every year. This study using the KCDC data was exempted from review by the IRB at Gangneung-Wonju National University (GWNUIRB-2016-07).

\section{Consent for publication}

- Not applicable

Availability of data and material

- The datasets used and/or analyzed during the current study are available from the corresponding author on reasonable request.

Competing interests

- The authors declare that they have no competing interests.

\section{Funding}

- Not applicable

\section{Authors' contributions}

- All authors contributed extensively to the work presented in this paper. BM has been involved in acquisition of data, analysis and interpretation of data and drafting the manuscript; $\mathrm{Jl}$ has made substantial contributions to conception and design, interpretation of data and drafting the manuscript; $\mathrm{SH}$ and $\mathrm{MH}$ have been revising it critically for important intellectual content; and All authors have given final approval of the version to be published. Each author have participated sufficiently in the work to take public responsibility for appropriate portions of the content and agreed to be accountable for all aspects of the work in ensuring that questions related to the accuracy or integrity of any part of the work are appropriately investigated and resolved.

\section{Acknowledgements}

- Not applicable

\section{References}

1. Kassebaum NJ, Bernabe E, Dahiya M, Bhandari B, Murray CJ, Marcenes W. Global burden of untreated caries: a systematic review and metaregression. J Dent Res. 2015, 94;5:650-658. 
2. Petersen PE, Bourgeois D, Ogawa $H$, Estupinan-Day $S$, Ndiaye $C$. The global burden of oral diseases and risks to oral health. Bull World Health Organ. 2005, 83;9:661-669.

3. Petersen PE. World Health Organization global policy for improvement of oral health-World Health Assembly 2007. Int Dent J. 2008, 58;3:115-121.

4. Schwendicke F, Dorfer CE, Schlattmann P, Foster Page L, Thomson WM, Paris S. Socioeconomic inequality and caries: a systematic review and meta-analysis. J Dent Res. 2015, 94;1:10-18.

5. Griffin SO, Wei L, Gooch BF, Weno K, Espinoza L. Vital Signs: Dental Sealant Use and Untreated Tooth Decay Among U.S. School-Aged Children. MMWR Morb Mortal Wkly Rep. 2016, 65;41:1141-1145.

6. Community Preventive Serivces Task Force. Oral Health: Preventing Dental Caries, School-Based Dental Sealant Delivery Programs: Community Preventive Serivces Task Force; 2016.

7. Griffin S, Naavaal S, Scherrer C, Griffin PM, Harris K, Chattopadhyay S. School-Based Dental Sealant Programs Prevent Cavities And Are Cost-Effective. Health affairs. 2016, 35;12:2233-2240.

8. Niederman R, Huang SS, Trescher AL, Listl S. Getting the Incentives Right: Improving Oral Health Equity With Universal School-Based Caries Prevention. Am J Public Health. 2017, 107;S1:S50-S55.

9. Liu W, Xiong L, Li J, Guo C, Fan W, Huang S. The anticaries effects of pit and fissure sealant in the first permanent molars of school-age children from Guangzhou: a population-based cohort study. BMC oral health. 2019, 19;1:156.

10. Verlinden DA, Reijneveld SA, Lanting Cl, van Wouwe JP, Schuller AA. Socio-economic inequality in oral health in childhood to young adulthood, despite full dental coverage. Eur J Oral Sci. 2019, 127;3:248-253.

11. Andre Kramer AC, Petzold M, Hakeberg M, Ostberg AL. Multiple Socioeconomic Factors and Dental Caries in Swedish Children and Adolescents. Caries Res. 2018, 52;1-2:42-50.

12. Amiresmaili M, Amini S, Shahravan A, Goudarzi R, Anari SHS, Anbari Z, Ghanbarnejad M. Relation between Socioeconomic Indicators and Children Dental Caries in Iran: A Systematic Review and Meta-analysis. Int J Prev Med. 2018, 9:71.

13. Chi DL, Masterson EE, Carle AC, Mancl LA, Coldwell SE. Socioeconomic status, food security, and dental caries in US children: mediation analyses of data from the National Health and Nutrition Examination Survey, 2007-2008. Am J Public Health. 2014, 104;5:860-864.

14. Kim HN, Han DH, Jun EJ, Kim SY, Jeong SH, Kim JB. The decline in dental caries among Korean children aged 8 and 12 years from 2000 to 2012 focusing SiC Index and DMFT. BMC oral health. 2016, 16:38.

15. Natioal Health Insurance extend the coverage for cancer and dental care [http://www.mohw.go.kr/react/al/sal0301vw.jsp? PAR_MENU_ID=04\&MENU_ID =0403\&page =574\&CONT_SEQ=215388]

16. Choi JS, Park DY. The impact of national health insurance coverage on pit and fissure sealing experience. Rural Remote Health. 2018, 18;4:4804. 
17. Sohn M, Park S, Lim S, Park HJ. Children's Dental Sealant Use and Caries Prevalence Affected by National Health Insurance Policy Change: Evidence from the Korean National Health and Nutrition Examination Survey (2007-2015). Int J Environ Res Public Health. 2019, 16;15.

18. Kim J, Choi Y, Park S, Kim JL, Lee TH, Cho KH, Park EC. Disparities in the experience and treatment of dental caries among children aged 9-18 years: the cross-sectional study of Korean National Health and Nutrition Examination Survey (2012-2013). Int J Equity Health. 2016, 15:88.

19. Manton DJ. Child Dental Caries - A Global Problem of Inequality. EClinicalMedicine. 2018, 1:3-4.

20. Kweon S, Kim Y, Jang MJ, Kim Y, Kim K, Choi S, Chun C, Khang YH, Oh K. Data resource profile: the Korea National Health and Nutrition Examination Survey (KNHANES). Int J Epidemiol. 2014, 43;1:6977.

21. Korea National Health \&Nutrition Examination Survey [https://knhanes.cdc.go.kr/knhanes/eng/index.do]

22. Korea Centers for Disease Control and Prevention(KCDC). Korea Health Statistics 2007 :Korea National Health and Nutrition Examination Survey(KNHANESIV-1): Ministry of Health and Welfare; 2008.

23. Korea Centers for Disease Control and Prevention(KCDC). Korea Health Statistics 2008 :Korea National Health and Nutrition Examination Survey(KNHANESIV-2): Ministry of Health and Welfare; 2009.

24. Korea Centers for Disease Control and Prevention(KCDC). Korea Health Statistics 2009 :Korea National Health and Nutrition Examination Survey(KNHANESIV-3): Ministry of Health and Welfare; 2010 .

25. Korea Centers for Disease Control and Prevention(KCDC). Korea Health Statistics 2013 :Korea National Health and Nutrition Examination Survey(KNHANESVI-1): Ministry of Health and Welfare; 2014.

26. Korea Centers for Disease Control and Prevention(KCDC). Korea Health Statistics 2014 :Korea National Health and Nutrition Examination Survey(KNHANESVI-2): Ministry of Health and Welfare; 2015.

27. Korea Centers for Disease Control and Prevention(KCDC). Korea Health Statistics 2015 :Korea National Health and Nutrition Examination Survey(KNHANESVI-3): Ministry of Health and Welfare; 2016.

28. World Health Organization. Oral health surveys : basic methods, 5th edn. Geneva: World Health Organization; 2013.

29. Korea Centers for Disease Control \& Prevention. Standardization for Oral Health Survey in KNHANES (2007); 2008.

30. Korea Centers for Disease Control \& Prevention. Standardization for Oral Health Survey in KNHANES (2008); 2009.

31. Korea Centers for Disease Control \& Prevention. Standardization for Oral Health Survey in KNHANES (2009); 2010. 
32. Korea Centers for Disease Control \& Prevention. Standardization for Oral Health Survey in KNHANES (2013); 2014.

33. Korea Centers for Disease Control \& Prevention. Standardization for Oral Health Survey in KNHANES (2014); 2015.

34. Korea Centers for Disease Control \& Prevention. Standardization for Oral Health Survey in KNHANES (2015); 2016.

35. Mackenbach JP, Kunst AE. Measuring the magnitude of socio-economic inequalities in health: an overview of available measures illustrated with two examples from Europe. Soc Sci Med. 1997, 44;6:757-771.

36. Harper S, King NB, Meersman SC, Reichman ME, Breen N, Lynch J. Implicit value judgments in the measurement of health inequalities. The Milbank quarterly. 2010, 88;1:4-29.

37. Harper S, Lynch JW. Measuring health inequalities. In: Methods in Social Epidemiology. edn. Edited by Oakes JM, Kaufman JS. San Fransisco: John Wiley \& Sons; 2006: 134-168.

38. Chang Y, Kang HY, Lim D, Cho HJ, Khang YH. Long-term trends in smoking prevalence and its socioeconomic inequalities in Korea, 1992-2016. Int J Equity Health. 2019, 18;1:148.

39. Yoo S, Cho HJ, Khang YH. General and abdominal obesity in South Korea, 1998-2007: gender and socioeconomic differences. Prev Med. 2010, 51;6:460-465.

40. Brown T, Platt S, Amos A. Equity impact of interventions and policies to reduce smoking in youth: systematic review. Tob Control. 2014, 23;e2:e98-105.

41. Lorenc T, Petticrew M, Welch V, Tugwell P. What types of interventions generate inequalities?

Evidence from systematic reviews. J Epidemiol Community Health. 2013, 67;2:190-193.

42. Thomson K, Hillier-Brown F, Todd A, McNamara C, Huijts T, Bambra C. The effects of public health policies on health inequalities in high-income countries: an umbrella review. BMC Public Health. 2018, 18;1:869.

43. Iheozor-Ejiofor Z, Worthington HV, Walsh T, O'Malley L, Clarkson JE, Macey R, Alam R, Tugwell P, Welch V, Glenny AM. Water fluoridation for the prevention of dental caries. Cochrane database of systematic reviews. 2015;6:CD010856.

44. de Silva AM, Hegde S, Akudo Nwagbara B, Calache H, Gussy MG, Nasser M, Morrice HR, Riggs E, Leong PM, Meyenn LK et al. Community-based population-level interventions for promoting child oral health. Cochrane database of systematic reviews. 2016, 9:CD009837.

45. Yu ZJ, Elyasi M, Amin M. Associations among dental insurance, dental visits, and unmet needs of US children. J Am Dent Assoc. 2017, 148;2:92-99.

46. Kumar JV, Tavares V, Kandhari P, Moss M, Jolaoso IA. Changes in Caries Experience, Untreated Caries, Sealant Prevalence, and Preventive Behavior Among Third-Graders in New York State, 20022004 and 2009-2012. Public health reports. 2015, 130;4:355-361.

47. Rougeaux E, Hope S, Law C, Pearce A. Have health inequalities changed during childhood in the New Labour generation? Findings from the UK Millennium Cohort Study. BMJ Open. 2017, 7;1:e012868. 
48. Capurro DA, lafolla T, Kingman A, Chattopadhyay A, Garcia I. Trends in income-related inequality in untreated caries among children in the United States: findings from NHANES I, NHANES III, and NHANES 1999-2004. Community Dent Oral Epidemiol. 2015, 43;6:500-510.

49. Macek MD. Although the Magnitude Varied, Income-Related Inequalities in Untreated Dental Caries were Consistently Found among Young Children in 3 US Surveys. J Evid Based Dent Pract. 2016, 16;2:142-144.

50. van Zwieten A, Saglimbene V, Teixeira-Pinto A, Howell M, Howard K, Craig JC, Wong G. The Impact of Age on Income-Related Health Status Inequalities from Birth to Adolescence: A Systematic Review with Cross-Country Comparisons. J Pediatr. 2018, 203:380-390 e314.

51. Hart JT. The inverse care law. Lancet. 1971, 1;7696:405-412.

52. Watt G. The inverse care law today. Lancet. 2002, 360;9328:252-254.

53. Marmot M. An inverse care law for our time. BMJ. 2018, 362:k3216.

54. Kim ES, Kim BI, Jung HI. Does the national dental scaling policy reduce inequalities in dental scaling usage? A population-based quasi-experimental study. BMC oral health. 2019, 19;1:185.

55. McLaren L, McIntyre L, Kirkpatrick S. Rose's population strategy of prevention need not increase social inequalities in health. Int J Epidemiol. 2010, 39;2:372-377.

56. Baldini V, Tagliaferro EP, Ambrosano GM, Meneghim Mde C, Pereira AC. Use of occlusal sealant in a community program and caries incidence in high- and low-risk children. J Appl Oral Sci. 2011, 19;4:396-402.

57. Hsu CL, Lin WS, Lin CH, Liu J. The effect of professional fluoride application program for preschool children in Taiwan: An analysis using the National Health Insurance Research Database (NHIRD). J Dent Sci. 2018, 13;3:248-255.

58. Ravaghi V, Hargreaves DS, Morris AJ. Persistent Socioeconomic Inequality in Child Dental Caries in England despite Equal Attendance. JDR Clin Trans Res. 2019:2380084419872136. 